\title{
Correction to: A unified view of density-based methods for semi-supervised clustering and classification
}

\author{
Jadson Castro Gertrudes ${ }^{1}$ (D) Arthur Zimek ${ }^{2}$ - Jörg Sander ${ }^{3}$. \\ Ricardo J. G. B. Campello 4
}

Received: 15 July 2020 / Accepted: 20 July 2020 / Published online: 3 August 2020

(C) The Author(s) 2020

\section{Correction to: \\ Data Mining and Knowledge Discovery (2019) 33:1894-1952 https://doi.org/10.1007/s10618-019-00651-1}

The article, A unified view of density-based methods for semi-supervised clustering and classification, written by Jadson Castro Gertrudes, Arthur Zimek, Jörg Sander, Ricardo J. G. B. Campello, was originally published electronically on the publisher's internet portal (currently Springer-Link) on 23 August 2019 without open access. With the author(s)' decision to opt for Open Choice, the copyright of the article changed on 30 July 2020 to (C) The Author(s) 2020 and the article is forthwith distributed under the terms of copyright.

The original article has been corrected.

The original article can be found online at https://doi.org/10.1007/s10618-019-00651-1.

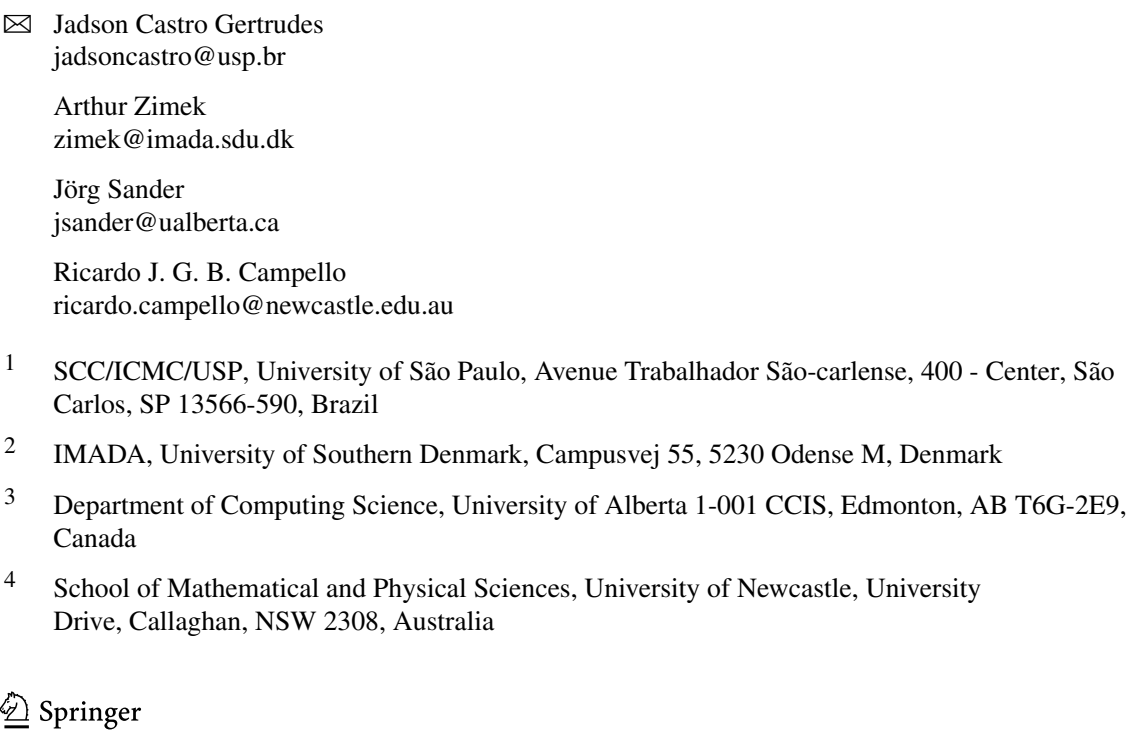


Open Access This article is distributed under the terms of the Creative Commons Attribution 4.0 International License (http://creativecommons.org/licenses/by/4.0/), which permits unrestricted use, distribution, and reproduction in any medium, provided you give appropriate credit to the original author(s) and the source, provide a link to the Creative Commons license, and indicate if changes were made.

Publisher's Note Springer Nature remains neutral with regard to jurisdictional claims in published maps and institutional affiliations. 